\title{
Uso da algarobeira (Prosopis juliflora) (Sw.) DC) no semiárido: o caso da Ribeira do Riacho do Navio
}

Use of the border (Prosopis juliflora) (Sw.) DC) in the semi-arid: the case of Ribeira do Riacho do Navio

Uso de la algarobeira (Prosopis juliflora) (Sw.) DC) en el semiárido: el caso de Ribeira do Riacho do Navio

Patrício Rinaldo dos Santos

Mestrando em Desenvolvimento e Meio Ambiente, PRODEMAIUFPE, Brasil patricioibimirim@hotmail.com

Fernando da Silva Alexandre Mestrando em Desenvolvimento e Meio Ambiente, PRODEMA IUFPE, Brasil fnando257@gmail.com

Maria Josiane de Lima Guedes Mestra em Administração e Desenvolvimento Rural, UFRPE, Brasil josiane.guedes2010@gmail.com

Fabriicia Gomes de Lucena Mestranda em Desenvolvimento e Meio Ambiente, PRODEMAIUFPE, Brasil fabriciagomes@gmail.com

Maria Luiza Coelho Cavalcanti Mestranda em Desenvolvimento e Meio Ambiente, PRODEMA JUFPE, Brasil malucoelhocavalcanti@gmail.com

Marcelo Olimpio dos Santos Mestrando em Desenvolvimento e Meio Ambiente, PRODEMA \UFPE, Brasil marolimpio@yahoo.com.br 
RESUMO

Objetivou-se com este estudo analisar a importância e os usos da algarobeira (Prosopis juliflora) para os agricultores da localidade ribeirinha do Riacho do Navio, município de Floresta, Estado de Pernambuco, Brasil. Campanhas de campo foram realizadas (visitas intercaladas, filmagens, registro fotográfico, observações diretas) e questionários semiestruturados foram efetivados em catorze localidades distintas com amostragem de 44 agricultores em áreas campesinas do Distrito de Airi, região ribeirinha do Riacho do Navio. Diante do exposto, os dados demonstram que a algarobeira foi trazida para a região a mais de 50 anos com intuito de servir de alimento para os rebanhos durante os prolongados períodos de estiagem e sombreamento nos terreiros das fazendas, aumentou sua colonização nos últimos 10 anos, a principal atividade econômica desenvolvida na região é a agricultura, sendo que o uso da planta dar-se especialmente para fins forrageiros e energéticos, cuja extração é desenvolvida nas propriedades de forma explorativa e terciária sem regularização de preços. Contudo, consideramos que os usuários indagados necessitam ser melhor capacitados para uso e gerenciamento adequado, e conscientizados das consequências da invasão provocada por esta planta.

PALAVRAS-CHAVE: Semiárido pernambucano. Agricultura. Prosipis juliflora

\begin{abstract}
The objective of this study was to analyze the importance and uses of the algarve (Prosopis juliflora) for farmers in the riverside town of Riacho do Navio, municipality of Floresta, State of Pernambuco, Brazil. Field campaigns were carried out (interleaved visits, filming, photographic record, direct observations) and semi-structured questionnaires were carried out in fourteen distinct locations with sampling of 44 farmers in peasant areas of the Airi District, riverside region of The Ship's Creek. In view of the above, the data show that the mesquite was brought to the region for more than 50 years in order to serve as food for the herds during the prolonged periods of drought and shading in the terraces of the farms, increased their colonization in the the main economic activity developed in the region is agriculture, and the use of the plant will be especially for forage and energy purposes, whose extraction is developed in the properties in an exploratory and tertiary way without price adjustment. However, we consider that the users asked need to be better trained for proper use and management, and aware of the consequences of plant invasion.
\end{abstract}

KEYWORDS: Semiarid pernambucano. Agriculture. Prosipis juliflora.

\title{
RESUMEN
}

El objetivo de este estudio fue analizar la importancia y los usos de la algarobeira (Prosopis juliflora) para los agricultores de la localidad ribereña de Riacho do Navio, municipio de Floresta, estado de Pernambuco, Brasil. Se llevaron a cabo campañas de campo (visitas intercaladas, rodaje, registro fotográfico, observaciones directas) y cuestionarios semiestructurados en catorce lugares diferentes con muestras de 44 agricultores en zonas campesinas de la Distrito de Airi, región ribereña de Riacho do Navio. En vista de lo anterior, los datos muestran que la algarobeira fue llevada a la región hace más de 50 años con el fin de servir como alimento para los rebaños durante los prolongados períodos de sequía y sombreado en las terrazas de las granjas, aumentó su colonización en el los últimos 10 años, la principal actividad económica desarrollada en la región es la agricultura, y el uso de la planta es especialmente para fines forrajeras y energéticos, cuya extracción se desarrolla en las propiedades de una manera exploratoria y terciaria sin ajuste de precios. Sin embargo, consideramos que los usuarios cuestionados necesitan estar mejor capacitados para un uso y gestión adecuados, y conscientes de las consecuencias de la invasión causada por esta planta.

PALABRAS CLAVE: Pernambuco semiárido. Agricultura. Juliflora Prosipis 


\section{INTRODUÇÃO}

No Brasil, a introdução da algaroba ocorreu em meados da década de 1940, no Sertão de Pernambuco, no município de Serra Talhada, a intenção era aumentar os recursos forrageiros da região e utilizar as árvores para reflorestar as áreas desmatadas do sertão (SILVA, 1989; SANTOS; DIODATO, 2019). Desta forma, alguns entusiastas dessa ideia defenderam a implementação da algarobeira, para a região semiárida, como espécie promotora do desenvolvimento regional para o país, devido a sua adaptação a temperaturas elevadas, solos pouco férteis, alta produtividade, resistência à seca, multiplicidade de usos da madeira (fornecimento de lenha, estacas para cercamento, carvão), que serviam por sua vez como matriz energética dos fornos, além de fonte alimentícia para os animais nos períodos de extrema seca e recurso para a apicultura (SILVA et al., 2012).

Apesar do clima adverso da região, a algarobeira adaptou-se muito rapidamente, sendo considerada uma árvore de múltiplos usos, ou seja, quando são cultivadas e manejadas com o propósito de atender aos interesses econômicos e aos interesses ambientais (ALMEIDA et al., 2008). Os produtos dessa arbórea, principalmente as vagens, têm um alto valor econômico e social, isso justifica-se porque nos períodos de secas na região semiárida de Pernambuco, ela é a principal alternativa de alimentação para os rebanhos (ARAÚJO, et al., 2008).

A justificativa para se realizar este trabalho se dá, sobretudo, pelo conhecimento empírico da realidade, em que aparentemente percebe-se um aumento significativo da espécie algarobeira ao longo das matas ciliares, áreas de preservação permanente e subutilizadas pelos agricultores no Riacho do Navio, Floresta - PE, dificultando a regeneração de espécies nativas ou florísticas da caatinga. Percebe-se que existem diversificadas técnicas de manejo e de trabalho por outrora ou atualmente empregadas em desacordo com os métodos implementados no âmbito da restauração ambiental e recuperação de áreas degradadas.

Objetivou-se com este estudo analisar a importância e os usos da algarobeira para os agricultores da localidade ribeirinha do Riacho do Navio, município de Floresta, Estado de Pernambuco. Para tal intento, delineou-se três objetivos específicos, a saber: a) Identificar as percepções dos sujeitos em relação aos benefícios ou malefícios do uso da algarobeira no território; b) Caracterizar os usos da algarobeira na região de estudo; c) Verificar de que maneira a arbórea contribui como fonte de renda para a população usuária.

\section{METODOLOGIA}

\section{1 Área de estudo}

O recorte espacial deste estudo está localizado na ribeira do Riacho do Navio, município de Floresta, Sertão do estado de Pernambuco, região Semiárida do Nordeste brasileiro (figura 1). 0 município de Floresta situa-se no semi-árido pernambucano, na mesorregião do São Francisco, distando aproximadamente 432,2 km do Recife (835'60"S, 3834'05"W) (FERRAZ, et al., 2006a). 
O riacho do Navio, afluente mais importante do rio Pajeú e situado em sua margem esquerda, nasce no município de Betânia e possui, na divisa deste com o município de Floresta, a barragem Barra do Juá. Da jusante da barragem Barra do Juá até a desembocadura, o riacho possui a extensão de 70,45 km, onde ocorrem as associações de solos aluviais salínicos e/ou sódicos com solos aluviais solódicos e não solódicos todos eutróficos, e de planossolos e solonetz mais solos litólicos, afloramentos rochosos e bruno não-cálcicos (EMBRAPA, 1999; FERRAZ, et al., 2006b). De acordo com a classificação de Köppen, Floresta apresenta o clima do tipo BSw'h' (muito quente, semiárido, tipo estepe (JACOMINE et al., 1973; SILVA, et al., 2013a). A temperatura média anual é de 26,5 ㄷ $\mathrm{C}$ e as precipitações variam em torno de $623 \mathrm{~mm}$, concentrando-se nos meses de janeiro a maio, sendo março e abril os mais chuvosos. A evapotranspiração potencial média é de $1.646 \mathrm{~mm}$ ao ano, com déficit hídrico anual de $1.023 \mathrm{~mm}$ (EMBRAPA, 2001; SILVA, et al., 2013b).

A vegetação é basicamente composta por Caatinga (RODAL; SAMPAIO, 2002; FERRAZ, et al., 2006c), hiperxerófila com trechos de Floresta Caducifólia (CPRM, 2005; SILVA, et al., 2013c). Às margens do riacho do Navio, onde esse estudo foi realizado, ocorrem as chamadas "matinhas beiradeiras", (AB'SABER, 2000; FERRAZ, et al., 2006d). Dentre os cursos d'água que drenam a área em estudo, destaca-se o Rio Pajeú (cujo principal afluente é o Riacho do Navio, que é intermitente) deságua no Rio São Francisco (SILVA, et al., 2013d).

De acordo com o Censo Demográfico de 2010 o Índice de Desenvolvimento Humano Municipal (IDHM) para este município é de 0,626 e segundo dados do Censo 2010 o município possuía uma população de 29.285 habitantes com estimativa populacional de 32.873 habitantes para o ano de 2019. Possui uma densidade demográfica de $8,04 \mathrm{hab} / \mathrm{Km}^{2}$. A principal atividade é a pecuária extensiva, contando com um razoável rebanho caprino (IBGE 2003; FERRAZ, et al., 2006e; IBGE, 2018). O Distrito de Airi que possui quatro estabelecimentos comerciais, uma escola (grupo) municipal, uma igreja católica, um posto de saúde e 55 domicílios e suas adjacências, onde foram realizadas as coletas de dados, localiza-se a $42 \mathrm{~km}$ da sede do município de Floresta, localmente também conhecida como "Floresta do Navio" ou "Terra dos Tamarindos".

Para este estudo foram pesquisadas catorze localidades distintas (fazendas e sítios), incluindo o Distrito do Airi, na ribeira do Riacho do Navio no período de 30 de maio a 06 de junho de 2019. As localidades visitadas foram as seguintes, a saber: Distrito do Airi; Fazenda Olho D'água; Fazenda Rochedo; Fazenda Poço do Caboclo; Fazenda Caiçara; Fazenda Riacho do Navio; Fazenda Poço do Fumo; Fazenda Quebra-unha de Fora; Fazenda Ilha Grande; Fazenda Urubu; Fazenda Caldeirão; Fazenda Lages; Fazenda Rancho dos Homens; Fazenda Pipipan. 
Figura 1 - Localização da área de estudo.

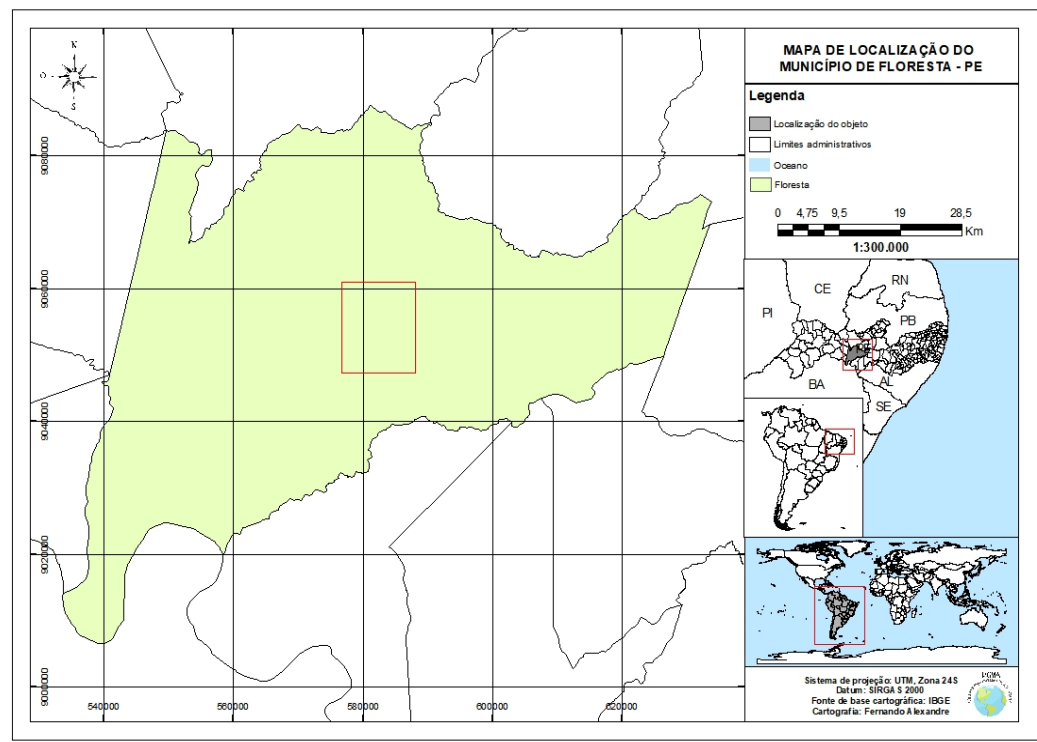

Fonte: Os autores, 2019

\subsection{Procedimento metodológico}

Para realização deste estudo foram feitos levantamentos bibliográficos a respeito da introdução da algarobeira no Semiárido do Nordeste brasileiro e seus desdobramentos ambientais, econômicos e sociais que serviram como arcabouço teórico para melhor compreensão dos aspectos positivos ou negativos causados pela Prosopis juliflora na região.

A pesquisa realizada é considerada de cunho qualitativo, nela tentou-se compreender os significados e características situacionais dos entrevistados, partindo do pressuposto que há uma relação dinâmica entre o objeto de estudo e o sujeito pesquisado (RICHARDSON,1999; MATIAS-PEREIRA, 2010).

Dessa forma, foram realizadas campanhas de campo nas quais foram entrevistados 44 agricultores, residentes em áreas campesinas do Distrito de Airi, região ribeirinha do Riacho do Navio, com o objetivo de se obter informações e conhecimentos acerca do problema de pesquisa considerado. Nesta ocasião foram realizadas visitas intercaladas, filmagens e registro fotográfico da invasão da planta e observações diretas dos usos e extratos remanescentes do bioma caatinga invadidos pela espécie, sobretudo ao longo da ribeira do Riacho do Navio, lócus deste estudo.

Por se tratar de um trabalho qualitativo, realizou-se um estudo de campo no qual buscou-se atender aos objetivos por meio do aprofundamento de uma realidade específica. A pesquisa foi realizada mediante observação direta das atividades do grupo estudado e de entrevistas com informantes para captar as explicações e interpretações que ocorrem naquela realidade (GIL, 2008). Sobre este tipo de pesquisa o autor em destaque ainda argumenta que, "os estudos de campo apresentam muitas semelhanças como os de levantamentos. Os de levantamentos, procuram ser representativos de um universo definido e fornecer resultados caracterizados pela 
precisão estatística. Já os estudos de campo estudam-se um único grupo ou comunidade em termos de sua estrutura social, ou seja, ressaltando a interação de seus componentes" (GIL, 2008).

Deste modo, fez-se uso do questionário semiestruturado como instrumento de coleta dos dados, aplicado por meio de entrevistas (GIL, 2008; MATIAS-PEREIRA, 2010). Os dados adquiridos foram plotados e, posteriormente, analisados por meio do uso do aplicativo (software) gratuito Google Forms a partir das leituras realizadas e informações coletadas em campo.

\section{RESULTADOS E DISCUSSÃO}

Entre o público-alvo pesquisado encontram-se pessoas de ambos os sexos, porém a maioria dos entrevistados são do sexo masculino, cerca de $80 \%$, com faixa etária entre 25 e 60 anos de idade. O nível de escolaridade dos entrevistados incidiu entre o analfabetismo e os primeiros anos escolares. A maioria dos entrevistados $(86,4 \%)$, são proprietários das terras onde trabalham. Porém $83,7 \%$ não soube informar o tamanho de sua propriedade.

Inicialmente para este estudo buscou-se compreender os tipos de uso e conhecimento em relação à algarobeira (Prosopis juliflora) no território. Quando questionados à respeito da origem da planta, muitos responderam que a invasão da algarobeira se deu a mais de 50 anos e foi trazida para alimentação dos animais (gado, sobretudo) e se alastrou espontaneamente entre as propriedades, uma vez que anteriormente a espécie era usada somente para fins de sombreamento nos terreiros das fazendas das redondezas:

\footnotetext{
“Chegou em 70 num sei não. Sei que chegou às mudinha empacotada em caixa vindo aqui num sei de onde pegando com a maior delicadeza, mudando e aguando e sei que se espalhou" .......] - (Entrevistado n. 03, 31 de maio, 2019).

"Olhe foi nos anos 69 para 70, o povo plantava para fazer sombra, nesse tempo não botava baje não, eu lembro eu menino na escola. Eu via o pessoal aguando algaroba. Aí depois, não sei como foi nascendo em todo canto, depois o pessoal trazia de fora, e foi nascendo, os animais comendo e foi nascendo nas beiras dos riachos" (Entrevistado n. 09, 31 de maio, 2019).
}

Diante dos relatos expostos, pode-se averiguar com exatidão durante as visitas in loco a ocorrência de árvores de algarobeiras plantadas para fins de sombreamento com seus sistemas radiculares expostos nos terreiros de fazendas (figura 2 ). 
Figura 2 - Entrada da Fazenda Rancho dos Homens com algarobeiras (a,b).

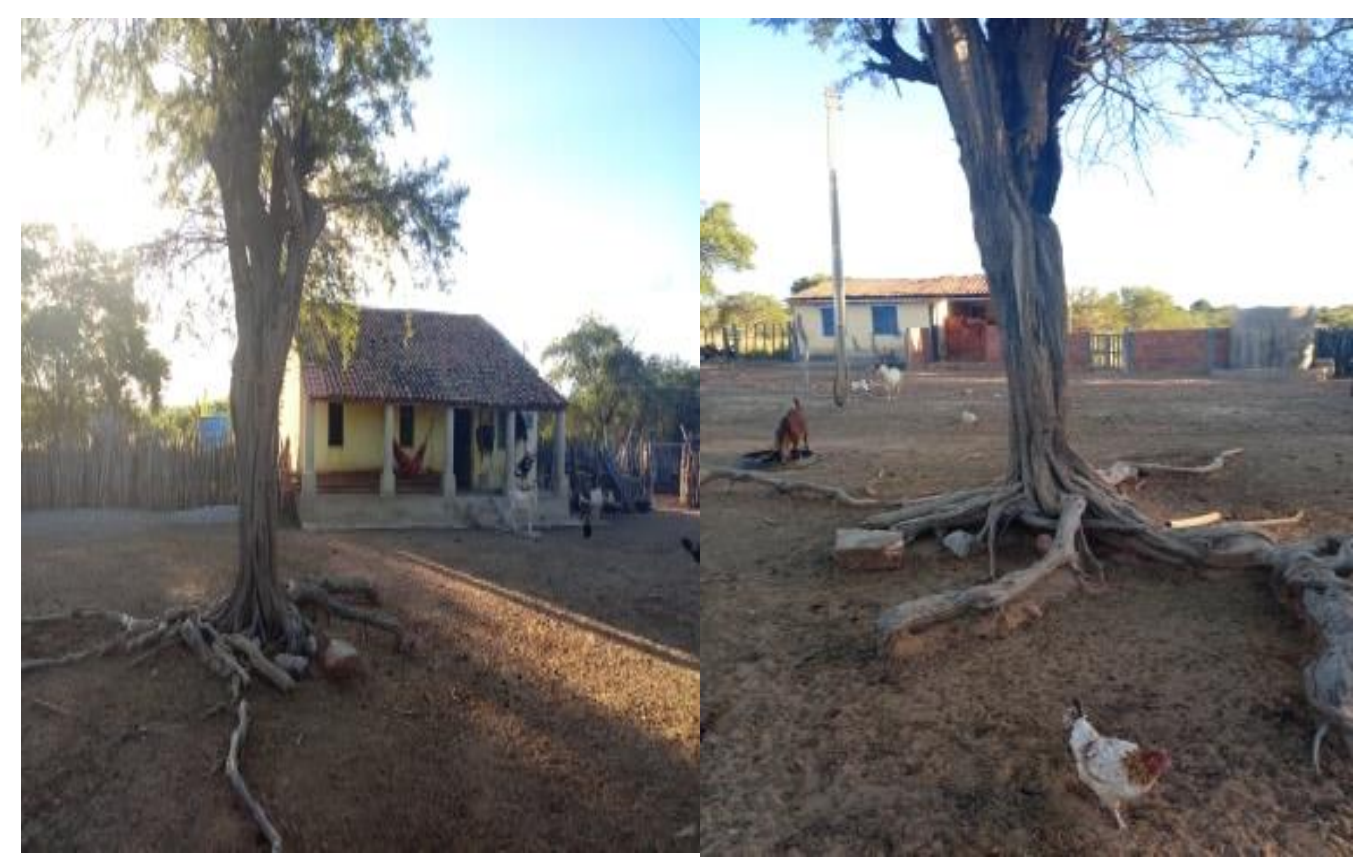

(A)

(B)

Fonte: Os autores, 2019.

Identificou-se em tais relatos, certo desconhecimento por parte dos entrevistados em relação à finalidade de implantação da algaroba no território, ao mesmo tempo, sensibilidade na percepção da evolução da espécie nas propriedades. Sabe-se que a implantação da daninha algarobeira se deu nos anos de 1940, cujos discursos do objetivo era a alimentação de animais. Porém, compreende-se que, quando implantada nos territórios, as populações que posteriormente se tornaram usuárias não foram orientadas tecnicamente sobre o manejo com a algarobeira. Tal conhecimento foi construído aos poucos pelos próprios usuários, cuja finalidade do uso atualmente se dá através da alimentação para os animais, produção de matriz energética (carvão, sobretudo) e sombra nas propriedades (figura 3):

"Diziam que iam servir de alimento para o gado..." (Entrevistado n. 11, 02 de junho, 2019).

"As primeiras mudas chegaram por boniteza. Era uma planta que se plantava em frente à casa para fazer sombra." (Entrevistado n. 12, 02 de junho, 2019).

No semiárido nordestino a trajetória da algarobeira - no curto espaço de tempo de 60 anos de planta salvadora que transformaria terras áridas em terras produtivas a protagonista de um desastre social e ambiental, denunciada como espécie invasora que acarreta problemas para os ecossistemas locais, apresenta-se neste sentido, como um importante campo para o estudo das relações entre seres humanos e natureza em contextos de mudança ambiental (CUNHA; SILVA, 2012). 
Neste sentido, questionou-se a respeito das percepções sobre a reprodução da algarobeira num determinado espaço de tempo. Em relação à propagação da algarobeira nos últimos 10 anos, a maioria das respostas é a respeito da continuidade da propagação e rearranjo do uso pelas próprias populações para outros fins:

"Aumentou muito. É tanto que o pessoal já está desmatando para fazer outras coisas como estacas, lenha" (Entrevistado n. 20, 03 de junho, 2019).

Estima-se que atualmente as áreas invadidas pela algaroba no Nordeste já se aproximam de um milhão de hectares (ANDRADE et al., 2010; SILVA; FABRICANTE, 2019). Em muitos relatos percebe-se a própria consciência dos usuários da algarobeira em relação às formas de uso, exploração da espécie:

\footnotetext{
"A algaroba diminuiu porque eu cortei muito mesmo. Cortei para fazer madeira, fazer carvão, aproveitando a lenha. Eu vendo, a gente faz carvão e eu vendo. É dividido. Eu nunca vendi lenha não, as estacas eu uso só nas cercas mesmos" (Entrevistado n. 25, 04 de junho, 2019).
}

Figura 3 - Lenha de algaroba pronta para o carrego e transporte no terreiro da Fazenda Urubu.

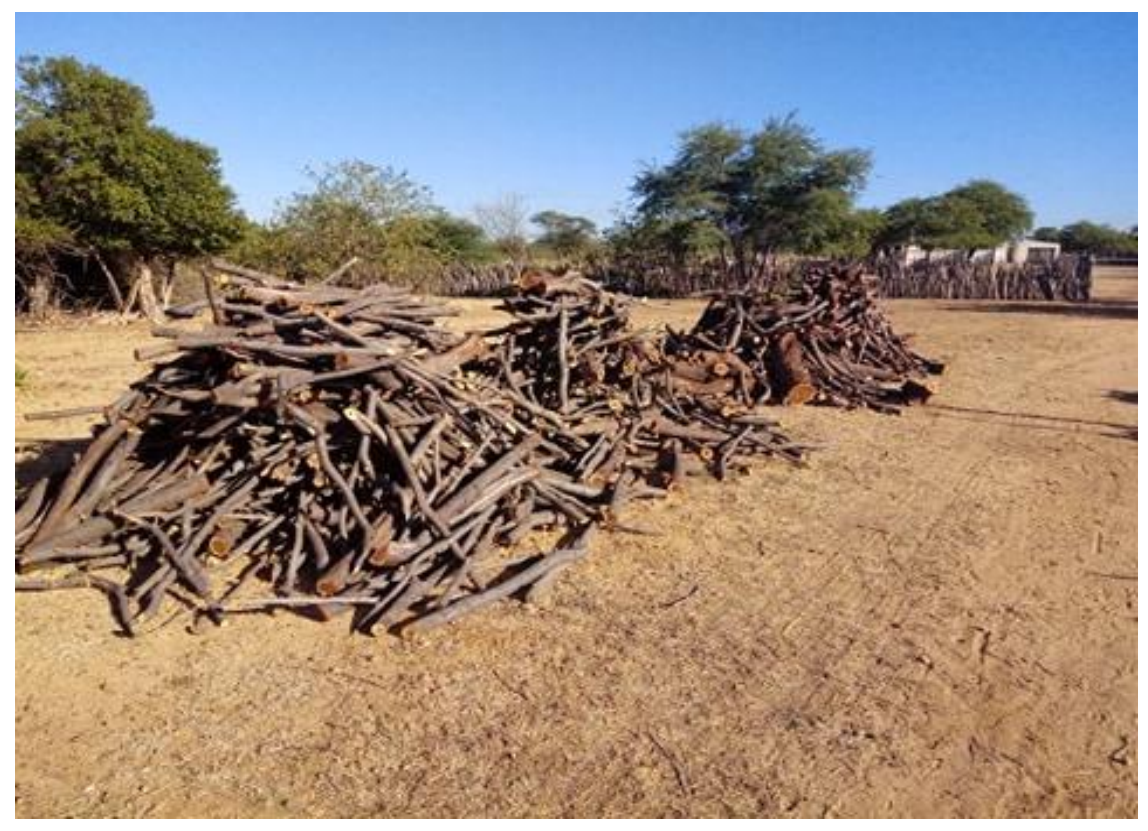

Fonte: Os autores, 2019.

Na coleta de dados, identificou-se também em que posição se encontra a produção da algarobeira entre as propriedades. Dentre os 44 agricultores pesquisados, com as respostas dadas, encontram-se respectivamente, a agricultura com 35 respostas, pecuária (representada 
pelas atividades de criação de bovinos, caprinos, ovinos, muares, burros, equinos) com 26 respostas, a extração da algarobeira com 21 respostas e outros com 12 respostas (gráfico 1).

\section{Gráfico 1 - Quantidade de respostas dadas pelos agricultores.}

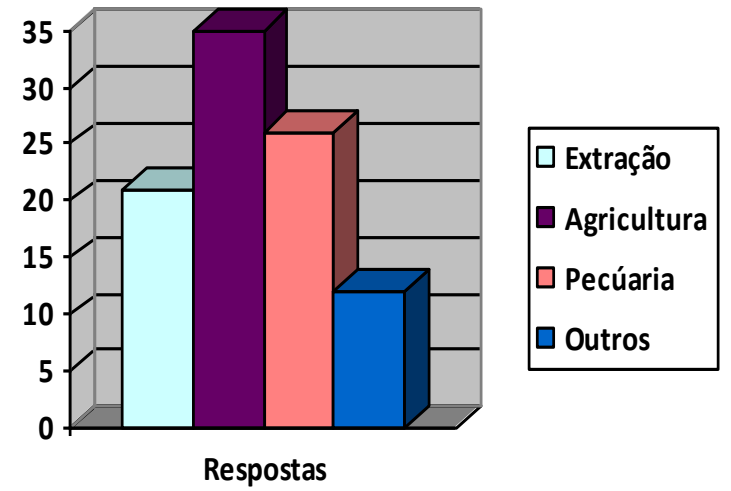

Fonte: Os autores, 2019.

As atividades destacadas são executadas em concomitância, ou seja, os entrevistados exercem mais de uma atividade do campo. Em relação às finalidades do uso da algarobeira, evidenciouse que os principais usos são na alimentação do gado, seguindo da venda de lenha, produção de carvão e venda de estacas e outras. As outras respostas dadas pelos agricultores não foram especificadas devido a todas elas terem apresentado somente 1 escolha.

Entre as formas de manejo e extração da algarobeira evidenciou-se que as atividades são desenvolvidas com equipamentos manuais de posse dos próprios extrativistas, ou por parte dos compradores de madeira:

\footnotetext{
"Corta de machado e motosserra" (Entrevistado n. 07, 31 de maio, 2019).

"É tudo por conta do comprador, a 16 reais o metro, dando 17,50 para os trabalhadores para colocar no ponto, a carrada para o dono da terra a 800" (Entrevistado n. 16, 03 de junho 2019).

"Corta com motosserra, ele faz o carvão e divide comigo. O carvão custa 11 reais aqui. Às vezes tiras uns 60 sacos outros 40 sacos. Eu pego o dinheiro para fazer o serviço mesmo, o carvão é do dono da terra" (Entrevistado n. 26, 04 de junho, 2019).
}

Quando questionados sobre a comercialização da algarobeira, as respostas evidenciaram que existe nesta localidade um processo de comercialização da lenha ou madeira entre os agricultores, proprietários de terras, extrativistas, compradores ou atravessadores. Porém sem regularização entre compra e venda. Isto vem ocorrendo devido ao crescimento de fábricas e 
algumas indústrias em determinadas áreas do Semiárido impactadas pela produção de cerâmica, do gesso, tijolos, pegmatitos; e até indústrias alimentícias, que demandam queima de lenha em grande escala para as produções.

\footnotetext{
"Vendo para o atravessador" (Entrevistado n. 03, 31 de maio, 2019);

"Vendo para um pessoal que vem de Sergipe" (entrevistados n. 2104 de junho, 2019).
}

Ainda quando questionados sobre qual renda consegue-se obter por período e em qual período, a maioria dos entrevistados não soube responder. Isso demonstra que a produção da algarobeira para lenha ou madeira é uma atividade desenvolvida nas propriedades de forma explorativa e terciária, sem regularização de preços e sem formalidade na relação entre compra e venda.

Nestas descrições percebe-se também a dinâmica das relações de trabalho entre compradores e vendedores da lenha da algarobeira, que serve tanto para a produção de carvão quanto para a produção de madeira. Ao mesmo tempo em que a extração da madeira fica por conta dos compradores - estes mais capitalizados para a comercialização, a venda inicial da matéria-prima é por um preço irrisório em comparação à venda no processo final do uso deste recurso da natureza, uma vez que a lenha, de modo geral, abastece desde a grande à pequena indústria e também é a mais barata, sendo a principal fonte energética no semiárido (BARBOSA, 2012). Outro objetivo da pesquisa de campo foi evidenciar a percepção dos usuários da algarobeira quanto aos impactos ao meio ambiente natural. Quando questionados se a espécie provoca algum impacto ambiental negativo ao meio ambiente e atividades agropastoris, cerca de $80 \%$ responderam que sim:

\footnotetext{
"Sim, se ela estiver próxima de uma casa ou caixa d'água destrói tudo por meio de suas raízes. Provoca rachaduras nas paredes, provoca invasão e se reproduz rápido. Para tração da terra tem que arrancar pela raiz" (entrevista n. 19. 03 de junho, 2019). E ainda: "Sim, se os bichos comerem a vagem molhada provoca malefício a ele" (entrevista n. 23. 04 de junho, 2019).
}

Identificou-se nesta questão várias respostas quanto aos malefícios da planta como: incompatibilidade de se adequar ao convívio com outras plantas, gerando a infertilidade do solo para outras plantações, doenças provocadas em animais devido a alimentação em demasiado, consumo e exorbitante dos recursos hídricos subterrâneos e superficiais.

Para Kassahun et. al., (2004); Abdulahi, Ute; Regasa (2017), a rápida expansão do Prosopis é considerada uma das principais ameaças, principalmente para a subsistência pastoral no meio ambiente, devido à sua natureza invasiva. Podem infestar pastagens, terras cultivadas irrigadas e canais de irrigação, causando finalmente um deslocamento irreversível de gramíneas naturais de pastagens e espécies nativas de árvores (figura 4). 
Figura 4 - Arbustos de algaroba no leito do Riacho do Navio, Fazenda Rancho dos Homens (a); Sombra de algaroba, terreiro da Fazenda Urubu (b).

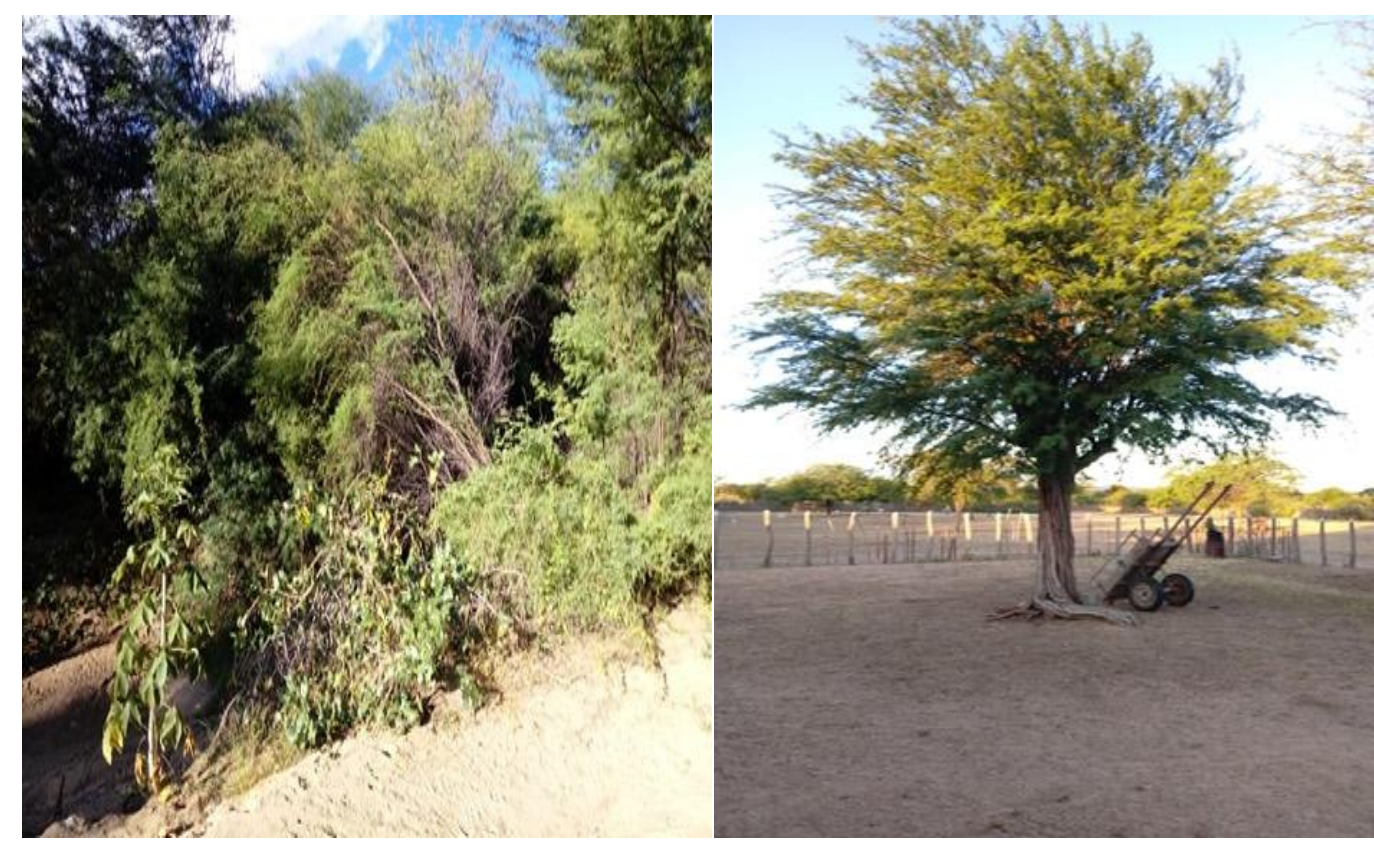

(a)

(B)

Neste sentido, percebe-se que a algarobeira é importante para a vivência dos agricultores no Distrito de Airi e adjacências, sendo uma fonte de alimento para os animais, sombreamento das áreas, produção de lenha e carvão para fins próprios e/ou comercialização. Porém, entre tantas possibilidades de uso desta planta invasora, são poucos os conhecimentos sobre a mesma. Compreende-se que o conhecimento existente acerca desta arbórea foi gerado entre os próprios usuários desde a implementação da algarobeira na região, tanto para os usos nas propriedades (alimentação para o gado, uso das estacas, etc.) como para fins de comercialização e como fonte energética (lenha, carvão, etc.); e especialmente as possíveis consequências da sua invasão ao meio ambiente. Desse modo, atributos positivos da invasão da algarobeira como a construção de materiais, lenha, esgrima, quebra-vento, tempestade de poeira e sombra, móveis e esculturas, vagens como forragem para animais e farinha de sementes para alimentos humanos, uso medicinal, fertilidade do solo, também foram identificados por Idyema (2011) na comunidade de Bura-Tana, Quênia, África.

Quando implantada inicialmente em 1946 em áreas secas do Nordeste do Brasil, através da política de reflorestamento, a "saga" da algaroba (Prosopis juliflora) no semiárido envolveu uma grande diversidade de atores sociais (técnicos, mídia e governos, pecuaristas), dentro do cenário desenvolvimentista pregava-se a introdução desta espécie como "salvação" socioeconômica para a região (BURNETT, 2017), devido à sua adaptação e resistência aos períodos de seca. Muitos estudos técnicos defendiam os seus benefícios para a terra e os animais, porém com o passar do tempo foram sendo necessários novos estudos para se averiguar os impactos de tal produção. 
A implantação da algarobeira no semiárido brasileiro passou por pelo menos três fases caracterizadas por complexas situações em termos de objetivos e prioridades. Ao mesmo tempo em que se reproduzia o discurso da "salvação" através do alimento para o gado e reflorestamento das áreas, não se desenvolviam estudos técnicos que evidenciam os impactos da produção desta espécie. $\mathrm{O}$ que ao final, o que se comprovou foram ações que acabaram por capitalizar os grandes proprietários, uma vez que os investimentos através da algarobeira se davam sobretudo, em propriedades privadas (SILVA, 2000; BURNETT, 2017).

Esses fatos referendam a Teoria de Schwarz \& Thompson (1990), que alega que tudo é tendencioso e parcial e mostra que os atores institucionais da "saga" da algaroba tinham suas preferências que influenciavam na hora das decisões sobre as escolhas tecnológicas para garantir a reprodução dos seus valores e criar vantagens em benefício próprio (BURNETT, 2017). Ao longo do tempo, muitos estudos acadêmicos foram e ainda estão sendo desenvolvidos sobre a existência da algarobeira no semiárido e os seus novos usos. Ao mesmo tempo, as populações locais desconhecem o objetivo de implantação desta árvore nos territórios do semiárido, bem como desconhecem a possibilidade de seus múltiplos usos e também chegam a considerá-la como uma árvore vilã.

De acordo com Franco (2015), a algaroba apresenta-se como uma matéria-prima viável à região semiárida porque possui diversos usos, a exemplos de outras realidades onde ela já foi implantada e foi capaz de movimentar a economia da região a partir de uma regularização do corte que atualmente é indiscriminado.

Segundo Burnett (2017), no caso da algaroba, "foi construído inicialmente um discurso de que a algaroba seria a "salvação" do Nordeste, ou seja, o "mito salvacionista". A partir de meados de 1990, iniciou-se a construção do "mito da vilã", baseado num discurso que a algaroba seria uma vilã da água, secando o solo e mananciais ao seu redor" (p.171). A autora cita estudos realizados pela Universidade Federal da Paraíba (UFPB), que evidenciam os processos de desmatamento em regiões do semiárido entre a Jurema e a Algaroba: "Os caminhões com carga de madeira de jurema são apreendidos, pois se trata de uma espécie protegida e, os de algaroba são liberados, pois se trata de uma espécie exótica. Esta política tem incentivado o desmatamento da algaroba como controle à sua invasão pela falta de manejo e, ao mesmo tempo, não incentiva o replantio" (BURNETT, 2017, p. 172).

Por se tratar de uma planta exótica, são necessários estudos para se demonstrar como vem sendo realizado o seu manejo. Primack e Rodrigues (2001, p.328) afirmam que "a introdução de espécies exóticas, representa uma ameaça à diversidade biológica, pois em algumas situações, as espécies exóticas se adaptam bem ao ambiente com efeitos negativos sobre as espécies nativas".

O processo de extração ou invasão sem controle da algaroba também são resultados dos processos de desertificação, construídos socialmente ao longo da história do semiárido. Barbosa (2012), descreve que este é um processo longo, lento e seus riscos são construídos socialmente. A desertificação,

...sucede porque os ecossistemas das terras áridas, semiáridas e subúmidas secas ficam em risco frente à exploração da terra, acima do suporte. As relações de capitais no campo têm degradado centenas de milhares de terras, 
ao longo dos anos, pelo uso exaustivo das terras. A desertificação não é um fenômeno natural, e sim, econômico. É a territorialização do capital (p. 312).

O desenvolvimento da pecuária extensiva, a agricultura itinerante e atualmente o agronegócio, bem como, a exploração de madeira através da lenha e carvão constituem as principais causas dessa devastação no semiárido historicamente, uma vez que a terra se torna mercadoria na geração do lucro para o capital. Neste sentido, a cada conjuntura política e ou econômica, são feitos novos rearranjos para exploração da natureza e dos recursos existentes, como é o caso da implantação da algaroba e o que vem resultando como seus múltiplos usos e formas de manejo nas regiões do semiárido.

\section{CONSIDERAÇÕES FINAIS}

Considerou-se que o estímulo à extração indiscriminada da algaroba no semiárido, vem a ser mais um dos discursos reproduzidos pela territorialização do capital na superexploração dos recursos da natureza. Assim como ocorreu a partir de 1945 como o debate do reflorestamento, o discurso atual da algaroba como vilã, serve como suporte à diminuição da retirada de outras plantas nativas em processo de extinção como a aroeira e umburana, ou contribui para se resolver impactos causados ao meio ambiente pelos próprios interesses dos atores sociais que a trouxeram à região.

Provavelmente, por trás da construção dos discursos quanto aos aspectos positivos ou negativos da invasão da algarobeira, estejam sendo mediados processos de desertificação do semiárido. Porém, estas são questões que precisam ser melhor estudadas para serem confirmadas, a partir de uma perspectiva crítica quanto à construção da ecologia política em torno do uso da algaroba.

Identificou-se o protagonismo dos entrevistados sobre a construção do próprio conhecimento acerca da algaroba no rearranjo da exploração da planta, tanto em suas propriedades quanto para fins de comercialização e alimentação de animais. Assim, considera-se necessário ações que provocam a preservação ambiental, visando a diminuição da influência da espécie sobre os recursos da natureza, como os recursos hídricos superficiais e subterrâneos, além da diminuição da proliferação de doenças nos rebanhos e o aumento do uso e utilização sustentável da espécie.

\section{AGRADECIMENTOS}

Aos agricultores da ribeira do Riacho do Navio, em Floresta - PE pela estimada atenção e participação na pesquisa, a Fundação de Amparo à Ciência e Tecnologia do Estado de Pernambuco - FACEPE e a Coordenação de Aperfeiçoamento de Pessoal de Nível Superior CAPES pela concessão das bolsas de pesquisa (Mestrado e Doutorado - PRODEMA/UFPE). 


\section{REFERÊNCIAS BIBLIOGRÁFICAS}

ABDULAHI, M.M.; UTE, J. A.; REGASA, T. Prosopis juliflora L: distribution, impacts and available control methods in Ethiopia. Tropical and Subtropical Agroecosystems, 20 (2017): 75 - 89.

AB'SABER, A.N. O suporte geoecológico das florestas beiradeiras (ciliares). Pp. 15-25. In: R.R. Rodrigues \& H.F. Leitão Filho (org.). Matas ciliares conservação e recuperação. São Paulo, EDUSP. 2000.

ALMEIDA, D; OLIVEIRA, W; SANTOS, Eduardo; LIMA, V; SILVA, J. Algaroba como fonte alternativa na produção de celulose. In: Congresso Internacional das Ciências Agrárias. 2008. Disponível em:< https://cointerpdvagro.com.br/wp-content/uploads/2019/01/ALGAROBA-COMO-FONT>. Acesso em: 11 dez. 2019.

ANDRADE, L. A.; FABRICANTE, J. R.; OLIVEIRA, F. X. Impactos da invasão de Prosopis julifl ora (sw.) DC. (Fabaceae) sobre o estrato arbustivo-arbóreo em áreas de Caatinga no Estado da Paraíba, Brasil. Acta Scientiarum Biological Sciences, 32(3):249-255. 2010.

ARAÚJO, J. L. P.; CORREIA, R. C.; ARAÚJO, E. P.; LIMA, P. C. F. Cadeia produtiva da algaroba no polo da Bacia do Submédio do São Francisco. Sociedade Brasileira de Economia, Administração e Sociologia Rural. 2008. Disponível em: <http://www.sober.org.br/palestra/5/371.pdf>. Acesso em: 27.06.2019.

BARBOSA, M. Territórios de insustentabilidade face ao processo de desertificação no semiárido brasileiro. In: GEHLEN, V. LAINÉ, P. Costurando com fios invisíveis: a fragmentação do território rural. Ed. universitária, UFPE, Recife, 2012 (p. 311-328).

BURNETT, A. A “saga” político-ecológica da algaroba no semiárido brasileiro. Rev. de Estudos Sociais. Cuiabá. v. 19, n. 28, p. 148. 2017.

COMPANHIA DE PESQUISA DE RECURSOS MINERAIS (CPRM). Serviço Geológico do Brasil. Projeto cadastro de fontes de abastecimento por água subterrânea. Diagnóstico do município de Floresta, Estado de Pernambuco, 2005. 33 p.

CUNHA, L. H.; SILVA, R. A. G. A trajetória da algaroba no semiárido nordestino: dilemas políticos e científicos. Raízes, v.32, n.1, jan-jun / 2012, p. 73-95.

EMPRESA BRASILEIRA DE PESQUISA AGROPECUÁRIA - EMBRAPA. 1999. Zoneamento agroecológico do estado de Pernambuco: mapa de reconhecimento de baixa-média intensidade de solos. Petrolina, mapa, color, $86 \mathrm{~cm} \times 68$ cm. Escala 1:100.000.

EMPRESA BRASILEIRA DE PESQUISA AGROPECUÁRIA (EMBRAPA). Diagnóstico Ambiental do Município de Floresta, Pernambuco. Rio de Janeiro-RJ: EMBRAPA, 2001. (Circular Técnica, ISSN 1517-5146). Disponível em: <http://www.cnps.embrapa.br/solosbr/pdfs/circulartecnica10diagamb floresta.pdf>. Acesso em: 11/05/2010.

FERRAZ, J. S. F.; ALBUQUERQUE, U. P.; MEUNIER, I. M. J. Valor de uso e estrutura da vegetação lenhosa às margens do Riacho do Navio, Floresta, PE, Brasil. Acta Botânica Brasílica. Belo Horizonte - MG. v. 20, n. (1), p. 125-134. 2006.

FRANCO, E. S. Biotecnologias adaptadas para o desenvolvimento sustentável do semiárido com o uso de Prosopis sp. 2015. 53 f. Monografia (Curso de Licenciatura em Geografia) - Departamento de Geografia, Universidade Federal da Paraíba. Campina Grande, 2015.

GIL, Antônio Carlos. Métodos e técnicas de pesquisa social. 6. Ed. São Paulo: Atlas, 2008.

IBGE. 2003. Site do Instituto Brasileiro de Geografia e Estatística. Disponível em: www.ibge.gov. Acesso em:15 de novembro de 2003.

IDYEMA, G. M. Integrated impact assessment of mesquite (Prosopis juliflora) on the livelihood of the Bura-Tana community, Kenya. MSc Thesis in Environmental Sciences, Environmental Systems Analysis Group. July. 2011. 
INSTITUTO BRASILEIRO DE GEOGRAFIA E ESTATÍSTICA - IBGE. Panorama de Floresta. Disponível em: https://cidades.ibge.gov.br/brasil/pe/floresta/panorama. Acesso em: 04 de jul.2019.

JACOMINE, P. K. T.; CAVALCANTI, A. C.; BURGOS, N.; PESSOA, S. C. P. Levantamento exploratório - reconhecimento de solos do Estado de Pernambuco. Recife, MA/DNPEA - SUDENE/DRN, 1973. v. 1. (Boletim técnico, 26).

MATIAS-PEREIRA, José. Manual de metodologia da pesquisa científica. 2. Ed. São Paulo: Atlas, 2010.

PRIMACK, R. B.; RODRIGUES, E. Biologia da conservação. Londrina: Editora Planta, 2001.

RICHARDSON, Roberto Jarry. Pesquisa Social: métodos e técnicas. 3. Ed. São Paulo: Atlas, 1999.

RODAL, M.J.N.; SAMPAIO, E.V.S.B. A vegetação do bioma caatinga. In: E.V.S.B. Sampaio; A.M. Giulietti; J. Virgínio \& C.F.L. Gamarra-Rojas (orgs.). Vegetação e Flora da Caatinga. Recife, APNE/ CNIP. 2002.

SANTOS, J. P. S., DIODATO, M. A.; GRIGIO, A.M.; FILHO, A. C. P. Distribuição e análise dos processos de dispersão de árvores do gênero Prosopis nas áreas de proteção permanente da área urbana do município de Mossoró /RN. Revista GEOTemas. Pau dos Ferros, Brasil. v. 9, n. 1, p. 161-181, jan./abr. 2019.

SCHWARZ, M. THOMPSON, M. Divided we stand: redefining politics, technology, and social choice. Philadelphia: University of Pennsylvania, 1990.

SILVA, E. A.; FERREIRA, R. L. C.; SILVA, J. A.A.; SÁ, I. B.; ARAÚJO, S.M. Dinâmica do uso e cobertura da terra do município de Floresta, PE. Revista FLORESTA, Curitiba, PR, v. 43, n. 4, p. 611 - 620, out. / dez. 2013.

SILVA, F. O.; FABRICANTE, J. R. Invasão biológica no Parque Nacional do Catimbau, Pernambuco, Brasil. Revista de Ciências Ambientais - RCA (UNILASALLE), Canoas, v. 13, n. 2, p. 00-10. 2019.

SILVA, Sebastião. História da Algaroba no Brasil. Teresina: SNPA\BN\EMBRAPA Meio-Norte, 2000.

SILVA, S. Algarobeira (Prosopis juliflora (Sw) D.C) no Nordeste do Brasil. Ministério da Agricultura, Secretaria Nacional de Produção Agropecuária, Secretaria da Produção Animal, Brasília, 1989. 